\title{
Microglial Scavenger Receptors and Their Roles in the Pathogenesis of Alzheimer's Disease
}

\author{
Kim Wilkinson and Joseph El Khoury \\ Center for Immunology and Inflammatory Diseases, Massachusetts General Hospital, Harvard Medical School, \\ Charlestown, MA, 02129, USA \\ Correspondence should be addressed to Kim Wilkinson, kwilkinson1@partners.org
}

Received 29 December 2011; Accepted 19 February 2012

Academic Editor: Lee-Way Jin

Copyright (๑) 2012 K. Wilkinson and J. El Khoury. This is an open access article distributed under the Creative Commons Attribution License, which permits unrestricted use, distribution, and reproduction in any medium, provided the original work is properly cited.

\begin{abstract}
Alzheimer's disease $(\mathrm{AD})$ is increasing in prevalence with the aging population. Deposition of amyloid- $\beta(\mathrm{A} \beta)$ in the brain of $\mathrm{AD}$ patients is a hallmark of the disease and is associated with increased microglial numbers and activation state. The interaction of microglia with $\mathrm{A} \beta$ appears to play a dichotomous role in $\mathrm{AD}$ pathogenesis. On one hand, microglia can phagocytose and clear $\mathrm{A} \beta$, but binding of microglia to $\mathrm{A} \beta$ also increases their ability to produce inflammatory cytokines, chemokines, and neurotoxic reactive oxygen species (ROS). Scavenger receptors, a group of evolutionally conserved proteins expressed on the surface of microglia act as receptors for $\mathrm{A} \beta$. Of particular interest are SCARA-1 (scavenger receptor A-1), CD36, and RAGE (receptor for advanced glycation end products). SCARA-1 appears to be involved in the clearance of A $\beta$, while CD36 and RAGE are involved in activation of microglia by $\mathrm{A} \beta$. In this review, we discuss the roles of various scavenger receptors in the interaction of microglia with $\mathrm{A} \beta$ and propose that these receptors play complementary, nonredundant functions in the development of AD pathology. We also discuss potential therapeutic applications for these receptors in $\mathrm{AD}$.
\end{abstract}

\section{Microglia and Alzheimer's Disease Pathology}

Alzheimer's disease $(\mathrm{AD})$ is a devastating neurological condition characterized by increasing memory loss, inability to perform daily tasks, and eventually dementia. This fatal condition currently has no cure, and by 2050, 13 million people in the United States are projected to be affected by the disease [1]. AD brains show deposition of the protein amyloid- $\beta(\mathrm{A} \beta)$ in senile plaques [2], this protein is produced by cleavage of APP (amyloid precursor protein), by the enzymes $\beta$-secretase and $\gamma$-secretase [3]. A $\beta$ accumulates in soluble form and also undergoes conformational changes to become fibrillar, microglia interact with both soluble and fibrillar forms of $A \beta[4-6]$.

In addition to $A \beta$ accumulation during the development of $\mathrm{AD}$, tau protein also accumulates in neurofibrillary tangles (NFT) in cell bodies of neurons [7] and apical dendrites [8]. Tau is a microtubule-associated protein that segregates into axons and stabilizes their microtubules. In $\mathrm{AD}$, tau dissociates from the microtubules and begins to accumulate in the somatodendritic compartment of the axon, a process which is not fully understood [9]. Tau contains a high number of phosphorylation sites and upon phosphorylation dissociates from the microtubules, as observed in AD [10]. Tau protein then undergoes conformational changes which form fibrils [11]. NFT could possibly activate microglia which may prove deleterious for the surrounding neurons and contribute to disease progression, however, little is known about the NFT mechanism of action [12].

Microglia are the major phagocytic cell of the brain and become activated upon encountering $\mathrm{A} \beta[6]$ and can release chemokines and cytokines into their environment [13]. Microglia are believed to initially clear $\mathrm{A} \beta$ deposits, but as the disease progresses, they produce proinflammatory cytokines, chemokines, and reactive oxygen species (ROS) and lose their ability to clear $A \beta[14]$, and despite increased numbers of microglia in the $\mathrm{AD}$ brain, the plaques continue to increase in size and number [15]. This inflammatory environment ultimately becomes toxic to the surrounding neurons, resulting in neuronal degeneration and disease progression [16]. 
Scavenger receptors bind many ligands with high affinity, including $\mathrm{A} \beta[4,17]$, and have been shown to be expressed on microglia surrounding $\mathrm{A} \beta$ plaques in the brain [18]. This review will focus on the role of scavenger receptors in $\mathrm{AD}$ development and discuss efforts to examine scavenger receptors as targets for therapy.

\section{What Are Scavenger Receptors (SRs)?}

Several families of pattern recognition receptors (PRR) have been identified including the well-defined and extensively studied Toll-like and Nod-like receptors (TLR and NLRs). In addition to these proteins, the scavenger receptor (SR) family represents another major class of PRR. SRs were first described in 1979 by Brown and Goldstein as macrophage receptors that mediate endocytosis of modified low-density lipoprotein (LDL) leading to foam cell formation and were shown to play a role in the pathogenesis of atherosclerosis $[19,20]$. Since then, the definition of SRs has been broadened: SRs are defined as a family of molecules that share the ability to bind polyanionic ligands. This simple definition belies the importance of SRs as PRRs-SRs are archetypal multifunctional receptors, often able to bind ligands of both pathogen and self-origin. These receptors are teleologically ancient pathogen receptors, emphasizing their important role in host defense. However, while the critical roles SRs play in atherosclerosis and host defense against a variety of pathogens is well characterized, the exact role of these receptors in the pathogenesis of neurodegenerative disorders including AD is not clearly understood.

\section{Classification of SRs}

SRs are structurally unrelated membrane receptors that are highly expressed by phagocytes such as macrophages, dendritic cells, and microglia, and also found on selected endothelial cells (Figure 1). To date, the SRs family has been classified into 6 classes but additional members of this family, like CD163, RAGE, and SR-PSOX (scavenger receptor that binds phosphatidylserine and oxidized lipoprotein) remain unclassified. SRs are defined by their common ability to bind polyanionic ligands with high affinity and have broad specificity. SRs cooperate with the other innate immune PRRs like the TLRs to define pathogen-specific responses [21]. However, unlike the TLRs and NLRs, SRs facilitate ligand uptake by phagocytosis and endocytosis [22].

\section{Class A Scavenger Receptors (SCARA)}

SCARA are required for host defense against several bacterial and viral pathogens: SCARA-1 is an arrangement of three coiled extracellular regions with cysteine-rich domains connected to the plasma membrane by a long fibrous stalk composed of an alpha-helical coiled coil and a collagen rich triple helix which is believed to bind ligands through the collagen-like domain [23-25] (Figure 1). SCARA-1 exemplify this family of multiligand receptors, in addition to binding to modified lipoproteins, lipopolysaccharide (LPS),

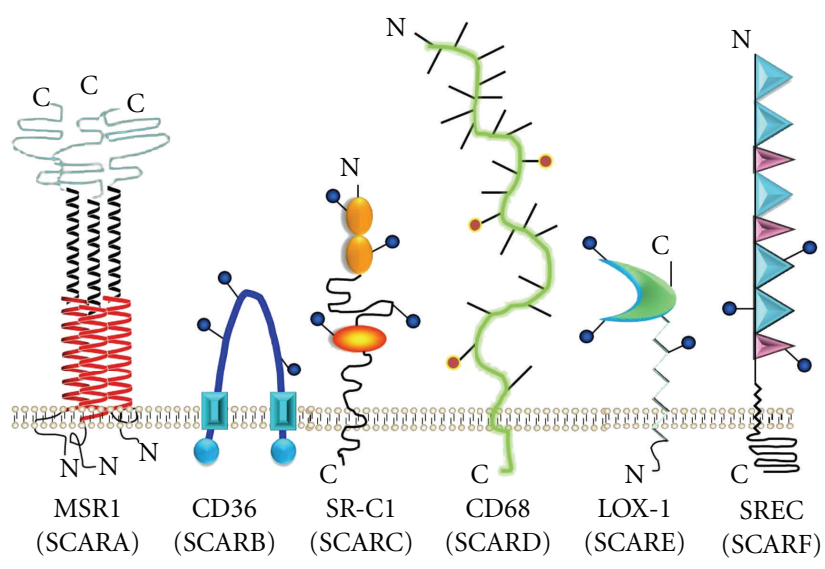

FIGURE 1: Structural diversity of the scavenger receptors. SCARA have a collagen-like domain believed to be their ligand-binding domain. CD68 has a mucin-like domain; LOX-1(oxidized-low density lipoprotein (lectin-like) receptor-1) (SCARE) has a C-type lectin domain and binds oxidized LDL. SCARF (scavenger receptor class F) has multiple extracellular EGF-like repeats.

[26] and lipoteichoic acid (LTA) [27, 28], we and others have shown that SCARA-1/2 also bind fibrillar $\beta$-amyloid and advanced glycosylation end products (AGEs) $[4,25]$. SCARA-1/2 mediate phagocytosis of infectious organisms like Staphylococcus aureus [28] and Neisseria meningitides [29] and also mediate clearance of apoptotic thymocytes [30]. Because of their broad ligand specificity, SCARA-1/2 contribute to resistance to gram-positive and gram-negative microbial infections and some viral infections in vivo, and SCARA-1/2 null mice succumb to $S$. aureus, and Herpes simplex infections faster than normal mice [28, 31]. In addition, SCARA-1/2 null mice also demonstrate increased susceptibility to LPS-induced shock, [32] suggesting a potential role in regulating the endotoxin response.

4.1. SCARA Role in Alzheimer's Disease. Murine microglia bind and phagocytose $A \beta$ via SCARA1. Studies using a transgenic mouse model of AD expressing the human form of $\mathrm{A} \beta$, and developing $\mathrm{A} \beta$ plaques in the brain over time [33] showed an increased level of SCARA-1 on microglia around $\mathrm{A} \beta$ plaques [34]. Microglia isolated from human brains were also able to bind to and ingest $A \beta$ via SCARA1 [35]. Additional evidence that SCARA-1 is an important phagocytic receptor for $\mathrm{A} \beta$ comes from studies using microglia from SCARA-1 knock-out mice. SCARA-1 knockout microglia isolated from these animals showed a $60 \%$ decrease in the ability to take up amyloid- $\beta$ compared with wild-type cells [36]. These results suggest that in addition to SCARA-1, other receptors may be involved in clearance of A $\beta$ by microglia. Since SCARA- 1 is involved in clearance of $\mathrm{A} \beta$, from a therapeutic standpoint, it may be beneficial to upregulate expression of this receptor on microglia thereby increasing the ability of these cells to clear $\mathrm{A} \beta$.

Another SCARA that has been shown to interact with $\mathrm{A} \beta$ is the macrophage scavenger receptor with collagenous structure (MARCO). MARCO is a SCARA family member 
but is encoded by a distinct gene from SCARA-1/2. Importantly, MARCO and SCARA1/2 have both common and distinct ligands $[37,38]$. MARCO is expressed on cultured neonatal rat microglia and is also a receptor for $\mathrm{A} \beta$ [39]. It is not known if MARCO is expressed in microglia in the $\mathrm{AD}$ brain. By coimmunoprecipitation, MARCO has been shown to form a complex with formyl peptide-receptor-like 1 (FPRL1) upon encountering A $\beta$. Intracellular signaling via ERK $1 / 2$ and inhibition of cAMP is then initiated through FPRL1 which may play a part in decreasing the inflammatory response mediated through MARCO in microglia [40].

\section{Class B Scavenger Receptors (SCARB)}

SCARB are also important in the innate host response to bacterial and fungal pathogens. The $\mathrm{B}$ class receptors are characterized by the presence of membrane-spanning $\mathrm{N}$ and $\mathrm{C}$ termini and a large extracellular loop [41] (Figure 1). CD36 (SCARB-2), the first classified SCARB was initially identified as a receptor for thrombospondin [42] and for malaria parasitized erythrocytes [43]. Endemann and colleagues subsequently identified CD36 as the "second" modified lipoprotein receptor [44], the first receptor being SCARA-1/2. By virtue of their ability to bind HDL and act as fatty acid transporters, CD36 and SCARB-1 play major roles in cholesterol metabolism [45-47]. CD36 also binds and internalizes $S$. aureus and is required for protection against this pathogen [21]. Recently, we have uncovered a novel role for CD36 as a receptor for $\beta$-glucan [48]. We also found that CD36 and its $C$. elegans ortholog play a major role in host defense to opportunistic infections with pathogenic yeast such as Candida albicans and Cryptococcus neoformans. Interestingly, SCARB-1 act as a coreceptor for the hepatitis C virus and may play a role in viral pathogenesis of hepatitis C $[49,50]$. In addition to binding to microbial ligands, CD36 binds several modified "self" antigens including AGEmodified proteins involved in the pathogenesis of vascular complications of diabetes [51].

5.1. SCARB Role in Alzheimer's Disease. Scavenger receptor $\mathrm{B} 1$ (SCARB-1) is a receptor for $\mathrm{A} \beta$ on microglia. A study by Husemann et al. [52] proposed that SCARB-1 is developmentally regulated and was not found on microglia in adult human brain and was only expressed on astrocytes. In a mouse model of $\mathrm{AD}$, a reduction in SCARB- 1 protein expression increased $\mathrm{A} \beta$ plaque deposition had no effect on microglial accumulation around $\mathrm{A} \beta$ plaques and in fact worsened cognitive defects in learning and memory [53].

CD36/SCARB-2 is also expressed on microglia and a receptor for amyloid- $\beta$ [54]. Intracellular signaling through CD36 is activated upon $\mathrm{A} \beta$ binding and activates microglia to produce cytokines and chemokines that induce microglial migration [55]. CD36 knock-out microglia have less A $\beta$ mediated activation and reduced chemokines and cytokine production compared with wild-type cells. Injection of $\mathrm{A} \beta$ into CD36 knock-out mouse brains induced less accumulation of microglia compared with wild-type brains, demonstrating an important role for CD36 in the inflammatory response to $\mathrm{A} \beta$ [54]. Microglial CD36 signals upon $\mathrm{A} \beta$ engagement via the Src family members Fyn and Lyn and by activation of mitogen-activated protein kinase (MAPK) and subsequent chemokine and ROS production [56].

Further investigation of the signaling properties of CD36 has recently been shown to be intimately involved with two toll-like receptors TLR- 4 and TLR- 6 . Upon A $\beta$ engagement, CD36 forms a heterodimeric complex with TLR-4 and TLR6 on microglia resulting in ROS production, and an increase in IL- $\beta$ mRNA, indicative of inflammasome activation [5].

From a therapeutic standpoint, it may be advantageous to inhibit the ability of CD36 to signal when bound to $\mathrm{A} \beta$, and thus prevent the release of chemokines and ROS by microglia that are deleterious to the surrounding neurons. We recently undertook a high-content screen to identify small molecule inhibitors of CD36. Screening of an FDAapproved compound library discovered ursolic acid to be an inhibitor of CD36 binding to $\mathrm{A} \beta$. In addition, ursolic acid also inhibited $\mathrm{A} \beta$-mediated ROS production in microglia without effecting microglial ability to phagocytose $\mathrm{A} \beta$ [57].

\section{Class C Scavenger Receptors (SCARC)}

SCARC-1 was identified in Drosophila but no mammalian ortholog for this receptor has yet been discovered. SCARC1 is involved in phagocytosis of Gram-negative and Grampositive bacteria but not yeast $[58,59]$. Intriguingly, SCARC1 also mediates uptake of dsRNA [59]. Since no mammalian ortholog for SCARC has been identified, it remains to be determined if this class of SR plays any role(s) in mammalian physiology or disease pathogenesis.

\section{Class D Scavenger Receptors (SCARD)}

The class D SRs are characterized by the presence of a mucinlike extracellular domain (Figure 1). The best characterized SCARD is CD68 (also known as macrosialin), which is expressed by macrophages, dendritic cells microglia, and osteoclasts [60, 61] For this reason, CD68 has been used for many years as a histological marker for these cells. It is found mainly intracellularly in late endosomes but cell surface expression increases following activation [62]. CD68/ macrosialin plays a minor role in the binding and uptake of oxidized lipoproteins and apoptotic cells by macrophages [63].

7.1. Role of SCARD in Alzheimer's Disease. Studies investigating a role of SCARD in AD have been mostly descriptive. Immunizing human subjects with $\mathrm{AD}$ with $\mathrm{A} \beta 1-42$ caused a reduction in plaques and an upregulation of CD68 expressed on microglia [64]. However in two longer surviving subjects, even though $\mathrm{A} \beta$ plaques were cleared, the expression of CD68 was found to be lower than in nonimmunized AD brains [65]. No studies to date investigated whether this class of SRs is mechanistically involved in CNS disorders including AD. 


\section{Class E Scavenger Receptors (SCARE)}

Lectin-like oxidized LDL receptor (LOX-1) was the first scavenger receptor with a C-type lectin-like domain (Figure 1) to be identified. LOX-1 was initially cloned from endothelial cells and appears to play a role in atherosclerosis [66]. LOX-1 is expressed on freshly isolated human monocytes [67], LOX-1 decreases with monocyte differentiation into macrophages. LOX-1 binds oxidized LDL [66] and has also been implicated in the transport of $\beta$-amyloid across the blood brain barrier $[68,69]$. In addition, LOX-1 binds gram positive and gram negative bacteria, although its exact role in the innate immune response to these pathogens is unknown [70]. It is not known if LOX-1 is expressed on microglia.

\section{Class F Scavenger Receptors-SCARF}

SCARFs are characterized by the presence of multiple extracellular epidermal growth factor-like repeats (Figure 1). The first SCARF was identified as an endothelial receptor for modified LDL, termed SREC [71]. In addition to binding modified LDL, SCARFs are receptors for heat shock proteins [72] and calreticulin which is involved in trafficking associated peptides into the major histocompatibility complex class I cross-presentation pathway of antigen-presenting cells [73]. We found that SCARF-1 is expressed on macrophages, and that SCARF-1 plays an important role in binding of the pathogenic yeasts Candida albicans and Cryptococcus neoformans. SCARF appears to be conserved through evolution. CED-1, a C. elegans ortholog of SCARF also appears to play a major role in the innate worm immune response to pathogenic yeast, and CED-1-deficient mutant worms have a dramatic increase in their susceptibility to these infections [48]. Interestingly, CED-1 also binds to cell corpses [74]. Similarly, related families of molecules have been identified in Drosophila melanogaster where they also contribute to host defense [75].

9.1. Role of SCARF in Alzheimer's Disease. It is not known if SCARF1 is expressed in the brain and/or involved in AD pathogenesis. MEGF10 (multiple EGF-like domains-10), also a member of the SCARF family, has recently been shown to be a receptor for $\mathrm{A} \beta$ [76]. MEGF10 is a type 1 transmembrane protein containing 17 EGF-like domains in the extracellular portion (Figure 1) [77]. MEGF10 is expressed in the brain of a transgenic mouse model of $\mathrm{AD}$ in the hippocampus and cortex region of the brain where $\mathrm{A} \beta$ plaques are also found, but it is unknown whether MEGF10 is expressed on microglia [76].

\section{Unclassified Scavenger Receptors}

10.1. RAGE. RAGE (receptor for advanced glycation end products) is a member of the immunoglobulin superfamily of receptors [78] expressed on endothelial cells [79] and microglia which is capable of binding many ligands including $\mathrm{A} \beta$ [80], AGEs (advanced glycation end products) and S100 protein [81]. Ligand binding to RAGE induces many intracellular signaling pathways such as Ras-extracellular signal-regulated kinase 1/2 (ERK1/2) [82], Cdc42/Race [83] stress-activated protein kinase/c-Jun-NH2-terminal kinase (SAPK/JNK), and p38 mitogen-activated protein (MAP) kinase pathways [84] that activate transcription factors, for example, $\mathrm{NF} \kappa \mathrm{B}$ [85], cAMP response element-binding (CREB) protein [82], or (STAT3), a member of the signal transducers and activators of transcription family [86]. RAGE activation through ligand binding induces a positive signaling feedback loop causing sustained activation of $N F \kappa B$ and a chronic state of inflammation [87].

10.1.1. Role of RAGE in Alzheimer's Disease. RAGE expressed on endothelial cells has previously been shown to play a role transporting $\mathrm{A} \beta$ into the brain [88], and also increasing the diapedesis of monocytes across the blood- brain barrier through RAGE-mediated signaling [89].

RAGE is expressed in higher levels on neurons and vasculature in AD brains compared with undiseased brains [90]. Soluble A $\beta$ bound to RAGE induces microglial activation and chemotaxis along a concentration gradient, which may lead to microglial accumulation around $\mathrm{A} \beta$ plaques. [80].

In a double-transgenic mouse model of $\mathrm{AD}$ (both expressing mutated human APP and increased levels of RAGE), A $\beta$ deposition, and microglial activation through $\mathrm{NF} \kappa \mathrm{B}$ were observed, providing evidence that RAGE also functions as a signaling receptor [91]. Studies using transgenic mice expressing human $\mathrm{A} \beta$ and a dominant negative form of RAGE showed microglial RAGE to be an essential signaling receptor, signaling through p38 MAPK and JNK, which leads to synaptic dysfunction through JNK-mediated IL- $\beta$ release [92].

However, more recent evidence shows that transgenic mice expressing both the Swedish and Arctic forms of human APP, and deficient in RAGE have a decrease in A $\beta$ deposition and an increase in insulin degrading enzyme (IDE), an enzyme known to cleave $\mathrm{A} \beta$ when compared to mice expressing RAGE [93]. Such decrease in $A \beta$ was found at 6 months of age. No improvement in cognitive function or difference in microglial recruitment to plaques was seen in 12 months old mice. This suggests RAGE may not be essential for microglial recruitment but could be involved in $\mathrm{A} \beta$ processing in the early disease state [94].

10.2. CD163. CD163 contains nine scavenger receptor cysteine-rich (SRCR) domains, an ancient and highly conserved protein motif, belonging to the SRCR superfamily. CD163 is expressed on mature tissue macrophages and has previously been shown to be involved in the clearance of hemoglobin-haptoglobin from the circulation [95]. Engagement of macrophage CD163-induced nitric oxide, IL- $1 \beta$, and $\mathrm{TNF} \alpha$ production, suggesting CD163 may be involved in activation of macrophages at sites of inflammation [96]. CD163 is also involved in host defense against both grampositive and gram-negative bacteria, acting as an immune sensor and mediator of inflammation [97]. In the brains of patients with HIV-associated dementia, CD163 was found to be expressed on microglia [98], and on perivascular 


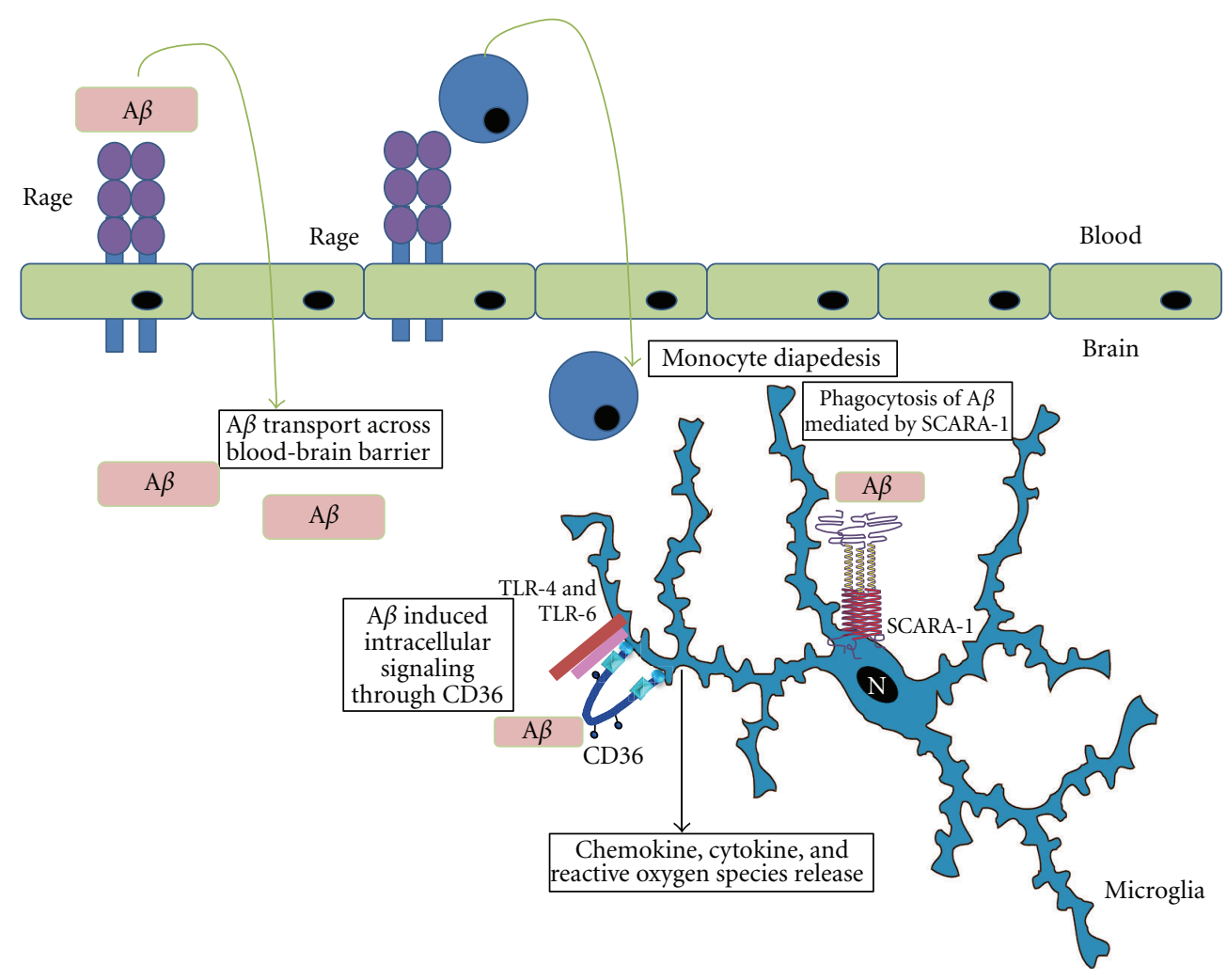

FIGURE 2: Diverse functions of SRs in development of Alzheimer's disease. RAGE facilitates transport of monocytes and A $\beta$ across the blood-brain-barrier, whereas SCARA-1 mediates internalization of A $\beta$ by microglia. CD36 and TLR- 4 and TLR- 6 ligation with A $\beta$ induces intracellular signaling and release of ROS, chemokines and cytokines.

macrophages near the blood-brain barrier, [99] and CD163 is considered a marker for perivascular macrophages. However it is unknown whether CD163 is involved in the pathogenesis of $\mathrm{AD}$.

10.3. SR-PSOX. Scavenger receptor that binds phosphatidylserine and oxidized lipids (SR-PSOX), also known as CXCL16, is a class H SR that can be both a membrane-bound and soluble protein. SR-PSOX is expressed on dendritic cells, and on monocyte-derived macrophages surrounding atherosclerotic plaques but not on smooth muscle cells or endothelial cells [100]. The membrane-bound form is composed of type I transmembrane glycoprotein, consisting of CXC chemokine, mucin stalk, transmembrane, and cytoplasmic domains [101]. Treatment of human peripheral blood mononuclear cells (PBMCs) with IFN $\gamma$ induced increased uptake of oxLDL and increased levels of SR-PSOX [102]. The soluble form of SR-PSOX has been shown to ligate the Tcell receptor CXCR6 and attracts IFN $\gamma$-producing T cells to lymph nodes [103]. It is not known if this receptor binds $\mathrm{A} \beta$ or whether it plays a role in $\mathrm{AD}$ pathogenesis.

\section{SR and Innate Immune Signaling}

A common emerging theme is that SRs are not only innate immune recognition and phagocytic receptors but also act as critical regulators of inflammatory signaling and function as sensors for the innate immune response. The mechanism(s) by which SRs regulate the outcome of ligand engagement is currently unknown.

Two potential and not mutually exclusive possibilities exist. First, SRs may facilitate ligand delivery to other PRRs, particularly to the TLRs, which have not been shown to be sufficient for cellular binding to their targets. Pertinent to this, recent work has demonstrated that many TLRs do not interact with their ligands on the cell surface but within intracellular compartments such as endosomes or phagosomes. However, the mechanisms that deliver TLR ligands to the appropriate compartments are poorly defined. One possibility is that ligand delivery is facilitated by coreceptors such as Dectins [104-107] and SRs. The second scenario is that signals triggered directly from the SRs combine with those from other PRRs to define the ligand-specific response.

Such dichotomous cooperative role of SRs with other PRRs is nicely illustrated by CD36. We have observed that CD36 knockout macrophages and microglia show a decreased response to bacterial and self-ligands including $\mathrm{A} \beta$ but expression of CD36 is not by itself sufficient to initiate such responses. CD36 requires the presence of TLRs to mediate the responses to its ligands [5]. This reflects two roles for CD36 which contributes to response by both binding the ligand and also by synergistic and cooperative signaling with other PRRS such as TLRs. This cooperation may define the specificity of the response to a particular ligand. Indeed, we found that CD36/TLR2/6 respond to pathogens [108] 
whereas CD36/TLR4/6 respond to endogenous ligands such as $\beta$-amyloid and oxLDL. These roles for CD36 have been mostly described in vitro. It remains to be determined if such sophisticated ligand-receptor specificity of interaction also occurs in vivo and whether it affects diseases processes such as $\mathrm{AD}$.

\section{Diverse Roles of SRs in AD}

Promising evidence has shown the diversity of SRs with regards to their functions during the development of $\mathrm{AD}$. SCARA-1 and CD36 play complementary nonredundant roles in the interactions of microglia with A $\beta$. SCARA-1$\mathrm{A} \beta$ interactions are beneficial and promote phagocytosis and clearance of $\mathrm{A} \beta$, whereas $\mathrm{CD} 36-\mathrm{A} \beta$ interactions are harmful and together with TLR- 4 and TLR- 6 lead to production of neurotoxins and proinflammatory molecules. This is reminiscent of the role CD36 plays in the interaction between macrophages and oxidized low-density lipoproteins in atherosclerosis. Indeed, we have shown in the past that while SCARA-1 mediates adhesion to oxidized LDL coated surfaces, CD36 mediates macrophage activation by oxidized LDL to produce reactive oxygen species [109]. Such differential roles of SCARA-1 and CD36 may have therapeutic implications for AD. Indeed, because of the role of SCARA-1 in $A \beta$ clearance, drugs that upregulate SCARA-1 expression or functions may be helpful for treatment of AD. In contrast, drugs that block CD36 interactions with $\mathrm{A} \beta$ or reduce its surface expression may be helpful to stop or delay progression of AD. Similarly, since RAGE expressed on endothelium facilitates the transport of circulating $A \beta$ from the blood across the blood-brain barrier into the brain, compounds that block $A \beta$-RAGE interactions may be beneficial. In addition to SCARA-1, CD36 and RAGE, and other SRs such as MARCO, LOX-1, and MEGF-10 are also emerging as receptors that bind $\mathrm{A} \beta$ and/or may have a role in the pathogenesis of disease (Figure 2). Dissecting the complex roles of various scavenger receptors in microglia- $\mathrm{A} \beta$ interactions, is therefore, important to understand the role of microglia in this disease and has therapeutic implications for treatment of this devastating disorder.

\section{Acknowledgments}

The work summarized in this manuscript was supported by NIH Grants NS059005, AG032349, AI082660 and a grant from the Dana Foundation Neuroimmunology Program to J. El Khoury

\section{References}

[1] J. J. Jalbert, L. A. Daiello, and K. L. Lapane, "Dementia of the Alzheimer type," Epidemiologic Reviews, vol. 30, no. 1, pp. 15-34, 2008.

[2] J. Näslund, V. Haroutunian, R. Mohs et al., "Correlation between elevated levels of amyloid $\beta$-peptide in the brain and cognitive decline," Journal of the American Medical Association, vol. 283, no. 12, pp. 1571-1577, 2000.
[3] G. Thinakaran and E. H. Koo, "Amyloid precursor protein trafficking, processing, and function," The Journal of Biological Chemistry, vol. 283, no. 44, pp. 29615-29619, 2008.

[4] J. El Khoury, S. E. Hickman, C. A. Thomas, L. Cao, S. C. Silverstein, and J. D. Loike, "Scavenger receptor-mediated adhesion of microglia to $\beta$-amyloid fibrils," Nature, vol. 382, no. 6593, pp. 716-719, 1996.

[5] C. R. Stewart, L. M. Stuart, K. Wilkinson et al., "CD36 ligands promote sterile inflammation through assembly of a toll-like receptor 4 and 6 heterodimer," Nature Immunology, vol. 11, no. 2, pp. 155-161, 2010.

[6] P. L. McGeer, S. Itagaki, H. Tago, and E. G. McGeer, "Reactive microglia in patients with senile dementia of the Alzheimer type are positive for the histocompatibility glycoprotein hladr," Neuroscience Letters, vol. 79, no. 1-2, pp. 195-200, 1987.

[7] A. Matus, "Microtubule-associated proteins and the determination of neuronal form," Journal De Physiologie, vol. 84, no. 1, pp. 134-137, 1990.

[8] J. Götz and L. M. Ittner, "Animal models of Alzheimer's disease and frontotemporal dementia," Nature Reviews Neuroscience, vol. 9, no. 7, pp. 532-544, 2008.

[9] L. M. Ittner, Y. D. Ke, F. Delerue et al., "Dendritic function of tau mediates amyloid- $\beta$ toxicity in Alzheimer's disease mouse models," Cell, vol. 142, no. 3, pp. 387-397, 2010.

[10] G. A. Jicha, R. Bowser, I. G. Kazam, and P. Davies, "Alz-50 and MC-1, a new monoclonal antibody raised to paired helical filaments, recognize conformational epitopes on recombinant tau," Journal of Neuroscience Research, vol. 48, no. 2, pp. 128132, 1997.

[11] J. D. Harper and P. T. Lansbury Jr., "Models of amyloid seeding in Alzheimer's disease and scrapie: mechanistic truths and physiological consequences of the time-dependent solubility of amyloid proteins," Annual Review of Biochemistry, vol. 66, pp. 385-407, 1997.

[12] M. I. Fonseca, R. R. Ager, S. H. Chu et al., "Treatment with a c5ar antagonist decreases pathology and enhances behavioral performance in murine models of Alzheimer's disease," Journal of Immunology, vol. 183, no. 2, pp. 1375-1383, 2009.

[13] M. Fiala, L. Zhang, X. Gan et al., "Amyloid- $\beta$ induces chemokine secretion and monocyte migration across a human blood-brain barrier model," Molecular Medicine, vol. 4, no. 7, pp. 480-489, 1998.

[14] C. Hale, M. Véniant, Z. Wang et al., "Structural characterization and pharmacodynamic effects of an orally active $11 \beta$-hydroxysteroid dehydrogenase type 1 inhibitor," Chemical Biology and Drug Design, vol. 71, no. 1, pp. 36-44, 2008.

[15] T. Bolmont, F. Haiss, D. Eicke et al., "Dynamics of the microglial/amyloid interaction indicate a role in plaque maintenance," Journal of Neuroscience, vol. 28, no. 16, pp. 4283-4292, 2008.

[16] S. E. Hickman, E. K. Allison, and J. El Khoury, "Microglial dysfunction and defective $\beta$-amyloid clearance pathways in aging Alzheimer's disease mice," Journal of Neuroscience, vol. 28, no. 33, pp. 8354-8360, 2008.

[17] D. M. Paresce, R. N. Ghosh, and F. R. Maxfield, "Microglial cells internalize aggregates of the Alzheimer's disease amyloid $\beta$-protein via a scavenger receptor," Neuron, vol. 17, no. 3, pp. 553-565, 1996.

[18] R. H. Christie, M. Freeman, and B. T. Hyman, "Expression of the macrophage scavenger receptor, a multifunctional lipoprotein receptor, in microglia associated with senile plaques in Alzheimer's disease," The American Journal of Pathology, vol. 148, no. 2, pp. 399-403, 1996. 
[19] J. L. Goldstein, Y. K. Ho, S. K. Basu, and M. S. Brown, "Binding site on macrophages that mediates uptake and degradation of acetylated low density lipoprotein, producing massive cholesterol deposition," Proceedings of the National Academy of Sciences of the United States of America, vol. 76, no. 1, pp. 333-337, 1979.

[20] M. Z. Ashraf and N. Gupta, "Scavenger receptors: implications in atherothrombotic disorders," International Journal of Biochemistry and Cell Biology, vol. 43, no. 5, pp. 697-700, 2011.

[21] L. M. Stuart, J. Deng, J. M. Silver et al., "Response to staphylococcus aureus requires CD36-mediated phagocytosis triggered by the cooh-terminal cytoplasmic domain," Journal of Cell Biology, vol. 170, no. 3, pp. 477-485, 2005.

[22] L. M. Stuart and R. A. B. Ezekowitz, "Phagocytosis: elegant complexity," Immunity, vol. 22, no. 5, pp. 539-550, 2005.

[23] T. Kodama, M. Freeman, L. Rohrer, J. Zabrecky, P. Matsudaira, and M. Krieger, "Type I macrophage scavenger receptor contains $\alpha$-helical and collagen-like coiled coils," Nature, vol. 343, no. 6258, pp. 531-535, 1990.

[24] L. Rohrer, M. Freeman, T. Kodama, M. Penman, and M. Krieger, "Coiled-coil fibrous domains mediate ligand binding by macrophage scavenger receptor type II," Nature, vol. 343, no. 6258, pp. 570-572, 1990.

[25] J. El Khoury, C. A. Thomas, J. D. Loike, S. E. Hickman, L. Cao, and S. C. Silverstein, "Macrophages adhere to glucosemodified basement membrane collagen iv via their scavenger receptors," The Journal of Biological Chemistry, vol. 269, no. 14, pp. 10197-10200, 1994.

[26] R. Y. Hampton, D. T. Golenbock, M. Penman, M. Krieger, and C. R. H. Raetz, "Recognition and plasma clearance of endotoxin by scavenger receptors," Nature, vol. 352, no. 6333, pp. 342-344, 1991.

[27] J. W. Greenberg, W. Fischer, and K. A. Joiner, "Influence of lipoteichoic acid structure on recognition by the macrophage scavenger receptor," Infection and Immunity, vol. 64, no. 8, pp. 3318-3325, 1996.

[28] C. A. Thomas, Y. Li, T. Kodama, H. Suzuki, S. C. Silverstein, and J. El Khoury, "Protection from lethal gram-positive infection by macrophage scavenger receptor-dependent phagocytosis," Journal of Experimental Medicine, vol. 191, no. 1, pp. 147-155, 2000.

[29] L. Peiser, M. P. J. De Winther, K. Makepeace et al., "The class A macrophage scavenger receptor is a major pattern recognition receptor for neisseria meningitidis which is independent of lipopolysaccharide and not required for secretory responses," Infection and Immunity, vol. 70, no. 10, pp. 53465354, 2002.

[30] N. Platt, H. Suzuki, Y. Kurihara, T. Kodama, and S. Gordon, "Role for the class A macrophage scavenger receptor in the phagocytosis of apoptotic thymocytes in vitro," Proceedings of the National Academy of Sciences of the United States of America, vol. 93, no. 22, pp. 12456-12460, 1996.

[31] H. Suzuki, Y. Kurihara, M. Takeya et al., "A role for macrophage scavenger receptors in atherosclerosis and susceptibility to infection," Nature, vol. 386, no. 6622, pp. 292296, 1997.

[32] Y. Kobayashi, C. Miyaji, H. Watanabe et al., "Role of macrophage scavenger receptor in endotoxin shock," Journal of Pathology, vol. 192, no. 2, pp. 263-272, 2000.

[33] C. Sturchler-Pierrat, D. Abramowski, M. Duke et al., "Two amyloid precursor protein transgenic mouse models with Alzheimer disease-like pathology," Proceedings of the National
Academy of Sciences of the United States of America, vol. 94, no. 24, pp. 13287-13292, 1997.

[34] K. D. Bornemann, K. H. Wiederhold, C. Pauli et al., “A $\beta$ induced inflammatory processes in microglia cells of APP23 transgenic mice," The American Journal of Pathology, vol. 158, no. 1, pp. 63-73, 2001.

[35] J. Husemann and S. C. Silverstein, "Expression of scavenger receptor class $B$, type $I$, by astrocytes and vascular smooth muscle cells in normal adult mouse and human brain and in Alzheimer's disease brain," The American Journal of Pathology, vol. 158, no. 3, pp. 825-832, 2001.

[36] H. Chung, M. I. Brazil, M. C. Irizarry, B. T. Hyman, and F. R. Maxfield, "Uptake of fibrillar $\beta$-amyloid by microglia isolated from MSR-A (type I and type II) knockout mice," Neuroreport, vol. 12, no. 6, pp. 1151-1154, 2001.

[37] S. Mukhopadhyay, Y. Chen, M. Sankala et al., "Marco, an innate activation marker of macrophages, is a class A scavenger receptor for neisseria meningitidis," European Journal of Immunology, vol. 36, no. 4, pp. 940-949, 2006.

[38] R. F. Hamilton Jr., S. A. Thakur, J. K. Mayfair, and A. Holian, "Marco mediates silica uptake and toxicity in alveolar macrophages from c57bl/6 mice," The Journal of Biological Chemistry, vol. 281, no. 45, pp. 34218-34226, 2006.

[39] R. Alarcón, C. Fuenzalida, M. Santibáñez, and R. von Bernhardi, "Expression of scavenger receptors in glial cells: Comparing the adhesion of astrocytes and microglia from neonatal rats to surface-bound $\beta$-amyloid," The Journal of Biological Chemistry, vol. 280, no. 34, pp. 30406-30415, 2005.

[40] L. O. Brandenburg, M. Konrad, C. J. Wruck, T. Koch, R. Lucius, and T. Pufe, "Functional and physical interactions between formyl-peptide-receptors and scavenger receptor marco and their involvement in amyloid beta 1-42-induced signal transduction in glial cells," Journal of Neurochemistry, vol. 113, no. 3, pp. 749-760, 2010.

[41] P. Gruarin, R. F. Thorne, D. J. Dorahy, G. F. Burns, R. Sitia, and M. Alessio, "CD36 is a ditopic glycoprotein with the n-terminal domain implicated in intracellular transport," Biochemical and Biophysical Research Communications, vol. 275, no. 2, pp. 446-454, 2000.

[42] A. S. Asch, J. Barnwell, R. L. Silverstein, and R. L. Nachman, "Isolation of the thrombospondin membrane receptor," Journal of Clinical Investigation, vol. 79, no. 4, pp. 1054-1061, 1987.

[43] C. F. Ockenhouse and J. D. Chulay, "Plasmodium falciparum sequestration: okm5 antigen (CD36) mediates cytoadherence of parasitized erythrocytes to a myelomonocytic cell line," Journal of Infectious Diseases, vol. 157, no. 3, pp. 584$588,1988$.

[44] G. Endemann, L. W. Stanton, K. S. Madden, C. M. Bryant, R. T. White, and A. A. Protter, "CD36 is a receptor for oxidized low density lipoprotein," The Journal of Biological Chemistry, vol. 268, no. 16, pp. 11811-11816, 1993.

[45] S. Acton, A. Rigotti, K. T. Landschulz, S. Xu, H. H. Hobbs, and M. Kriegert, "Identification of scavenger receptor SR-BI as a high density lipoprotein receptor," Science, vol. 271, no. 5248, pp. 518-520, 1996.

[46] N. A. Abumrad, M. R. El-Maghrabi, E. Z. Amri, E. Lopez, and P. A. Grimaldi, "Cloning of a rat adipocyte membrane protein implicated in binding or transport of long-chain fatty acids that is induced during preadipocyte differentiation. homology with human CD36," The Journal of Biological Chemistry, vol. 268, no. 24, pp. 17665-17668, 1993.

[47] C. M. Harmon and N. A. Abumrad, "Binding of sulfosuccinimidyl fatty acids to adipocyte membrane proteins: 
isolation and amino-terminal sequence of an $88-\mathrm{kD}$ protein implicated in transport of long-chain fatty acids," Journal of Membrane Biology, vol. 133, no. 1, pp. 43-49, 1993.

[48] T. K. Means, E. Mylonakis, E. Tampakakis et al., "Evolutionarily conserved recognition and innate immunity to fungal pathogens by the scavenger receptors scarf1 and CD36,' Journal of Experimental Medicine, vol. 206, no. 3, pp. 637-653, 2009.

[49] E. Scarselli, H. Ansuini, R. Cerino et al., "The human scavenger receptor class $\mathrm{B}$ type $\mathrm{I}$ is a novel candidate receptor for the hepatitis c virus," The EMBO Journal, vol. 21, no. 19, pp. 5017-5025, 2002.

[50] M. B. Zeisel, G. Koutsoudakis, E. K. Schnober et al., "Scavenger receptor class $\mathrm{B}$ type I is a key host factor for hepatitis $\mathrm{c}$ virus infection required for an entry step closely linked to cd81," Hepatology, vol. 46, no. 6, pp. 1722-1731, 2007.

[51] N. Ohgami, R. Nagai, M. Ikemoto et al., "CD36, serves as a receptor for advanced glycation endproducts (AGE)," Journal of Diabetes and its Complications, vol. 16, no. 1, pp. 56-59, 2002.

[52] J. Husemann, J. D. Loike, T. Kodama, and S. C. Silverstein, "Scavenger receptor class B type I (SR-BI) mediates adhesion of neonatal murine microglia to fibrillar $\beta$-amyloid," Journal of Neuroimmunology, vol. 114, no. 1-2, pp. 142-150, 2001.

[53] K. Thanopoulou, A. Fragkouli, F. Stylianopoulou, and S. Georgopoulos, "Scavenger receptor class B type I (SR-BI) regulates perivascular macrophages and modifies amyloid pathology in an Alzheimer mouse model," Proceedings of the National Academy of Sciences of the United States of America, vol. 107, no. 48, pp. 20816-20821, 2010.

[54] J. B. El Khoury, K. J. Moore, T. K. Means et al., "CD36 mediates the innate host response to $\beta$-amyloid," Journal of Experimental Medicine, vol. 197, no. 12, pp. 1657-1666, 2003.

[55] I. S. Coraci, J. Husemann, J. W. Berman et al., "CD36, a class B scavenger receptor, is expressed on microglia in Alzheimer's disease brains and can mediate production of reactive oxygen species in response to $\beta$-amyloid fibrils," The American Journal of Pathology, vol. 160, no. 1, pp. 101-112, 2002.

[56] K. J. Moore, J. El Khoury, L. A. Medeiros et al., "A CD36initiated signaling cascade mediates inflammatory effects of $\beta$-amyloid," The Journal of Biological Chemistry, vol. 277, no. 49, pp. 47373-47379, 2002.

[57] K. Wilkinson, J. D. Boyd, M. Glicksman, K. J. Moore, and J. El Khoury, "A high content drug screen identifies ursolic acid as an inhibitor of amyloid $\beta$ protein interactions with its receptor CD36," The Journal of Biological Chemistry, vol. 286, no. 40, pp. 34914-34922, 2011.

[58] A. Pearson, A. Lux, and M. Krieger, "Expression cloning of dsR-CI, a class C macrophage-specific scavenger receptor from drosophila melanogaster," Proceedings of the National Academy of Sciences of the United States of America, vol. 92, no. 9, pp. 4056-4060, 1995.

[59] M. Rämet, A. Pearson, P. Manfruelli et al., "Drosophila scavenger receptor $\mathrm{CI}$ is a pattern recognition receptor for bacteria," Immunity, vol. 15, no. 6, pp. 1027-1038, 2001.

[60] L. Martinez-Pomares, N. Platt, A. J. Mcknight, R. P. Da Silva, and S. Gordon, "Macrophage membrane molecules: markers of tissue differentiation and heterogeneity," Immunobiology, vol. 195, no. 4-5, pp. 407-416, 1996.

[61] D. R. Greaves and S. Gordon, "Macrophage-specific gene expression: current paradigms and future challenges," International Journal of Hematology, vol. 76, no. 1, pp. 6-15, 2002.
[62] S. Gordon, "Macrophage-restricted molecules: role in differentiation and activation," Immunology Letters, vol. 65, no. 12, pp. 5-8, 1999.

[63] Y. Yamada, T. Doi, T. Hamakubo, and T. Kodama, "Scavenger receptor family proteins: roles for atherosclerosis, host defence and disorders of the central nervous system," Cellular and Molecular Life Sciences, vol. 54, no. 7, pp. 628-640, 1998.

[64] A. Argiles, G. Mourad, P. G. Kerr, M. Garcia, B. Collins, and J. G. Demaille, "Cells surrounding haemodialysis-associated amyloid deposits are mainly macrophages," Nephrology Dialysis Transplantation, vol. 9, no. 6, pp. 662-667, 1994.

[65] E. Zotova, C. Holmes, D. Johnston, J. W. Neal, J. A. R. Nicoll, and D. Boche, "Microglial alterations in human Alzheimer's disease following a $\beta 42$ immunization," Neuropathology and Applied Neurobiology, vol. 37, no. 5, pp. 513-524, 2011.

[66] T. Sawamura, N. Kume, T. Aoyama et al., "An endothelial receptor for oxidized low-density lipoprotein," Nature, vol. 386, no. 6620, pp. 73-77, 1997.

[67] H. Yoshida, N. Kondratenko, S. Green, D. Steinberg, and O. Quehenberger, "Identification of the lectin-like receptor for oxidized low-density lipoprotein in human macrophages and its potential role as a scavenger receptor," Biochemical Journal, vol. 334, no. 1, pp. 9-13, 1998.

[68] E. Luedecking-Zimmer, S. T. DeKosky, Q. Chen, M. M. Barmada, and M. I. Kamboh, "Investigation of oxidized IDIreceptor 1 (ORI1) as the candidate gene for Alzheimer's disease on chromosome 12," Human Genetics, vol. 111, no. 4-5, pp. 443-451, 2002.

[69] J. Shi, J. Tian, A. Pritchard et al., “A 3'-UTR polymorphism in the oxidized ldl receptor 1 gene increases $A \beta 40$ load as cerebral amyloid angiopathy in Alzheimer's disease," Acta Neuropathologica, vol. 111, no. 1, pp. 15-20, 2006.

[70] T. Shimaoka, N. Kume, M. Minami et al., "LOX-1 supports adhesion of gram-positive and gram-negative bacteria," Journal of Immunology, vol. 166, no. 8, pp. 5108-5114, 2001.

[71] H. Adachi, M. Tsujimoto, H. Arai, and K. Inouel, "Expression cloning of a novel scavenger receptor from human endothelial cells," The Journal of Biological Chemistry, vol. 272, no. 50, pp. 31217-31220, 1997.

[72] J. G. Facciponte, X. Y. Wang, and J. R. Subjeck, "Hsp110 and Grp170, members of the Hsp70 superfamily, bind to scavenger receptor-A and scavenger receptor expressed by endothelial cell-I," European Journal of Immunology, vol. 37, no. 8, pp. 2268-2279, 2007.

[73] B. Berwin, Y. Delneste, R. V. Lovingood, S. R. Post, and S. V. Pizzo, "SREC-I, a type F scavenger receptor, is an endocytic receptor for calreticulin," The Journal of Biological Chemistry, vol. 279, no. 49, pp. 51250-51257, 2004.

[74] Z. Zhou, E. Hartwieg, and H. R. Horvitz, "CED-1 is a transmembrane receptor that mediates cell corpse engulfment in C. elegans," Cell, vol. 104, no. 1, pp. 43-56, 2001.

[75] C. Kocks, J. H. Cho, N. Nehme et al., "Eater, a transmembrane protein mediating phagocytosis of bacterial pathogens in drosophila," Cell, vol. 123, no. 2, pp. 335-346, 2005.

[76] T. D. Singh, S. Y. Park, J. S. Bae et al., "Megf10 functions as a receptor for the uptake of amyloid- $\beta$," FEBS Letters, vol. 584, no. 18, pp. 3936-3942, 2010.

[77] E. Suzuki and M. Nakayama, "The mammalian CED1 ortholog MEGF10/KIAA1780 displays a novel adhesion pattern," Experimental Cell Research, vol. 313, no. 11, pp. 2451-2464, 2007.

[78] M. Neeper, A. M. Schmidt, J. Brett et al., "Cloning and expression of a cell surface receptor for advanced glycosylation 
end products of proteins," The Journal of Biological Chemistry, vol. 267, no. 21, pp. 14998-15004, 1992.

[79] J. Brett, A. M. Schmidt, S. D. Yan et al., "Survey of the distribution of a newly characterized receptor for advanced glycation end products in tissues," The American Journal of Pathology, vol. 143, no. 6, pp. 1699-1712, 1993.

[80] S. D. Yan, X. Chen, J. Fu et al., "RAGE and amyloid- $\beta$ peptide neurotoxicity in Alzheimer's disease," Nature, vol. 382, no. 6593, pp. 685-691, 1996.

[81] E. Leclerc, G. Fritz, S. W. Vetter, and C. W. Heizmann, "Binding of S100 proteins to RAGE: an update," Biochimica Et Biophysica Acta, vol. 1793, no. 6, pp. 993-1007, 2009.

[82] H. J. Huttunen, J. Kuja-Panula, and H. Rauvala, "Receptor for advanced glycation end products (RAGE) signaling induces creb-dependent chromogranin expression during neuronal differentiation," The Journal of Biological Chemistry, vol. 277, no. 41, pp. 38635-38646, 2002.

[83] H. J. Huttunen, C. Fages, and H. Rauvala, "Receptor for advanced glycation end products (RAGE)-mediated neurite outgrowth and activation of NF- $\kappa \mathrm{B}$ require the cytoplasmic domain of the receptor but different downstream signaling pathways," The Journal of Biological Chemistry, vol. 274, no. 28, pp. 19919-19924, 1999.

[84] A. Taguchi, D. C. Blood, G. Del Toro et al., "Blockade of RAGE-amphoterin signalling suppresses tumour growth and metastases," Nature, vol. 405, no. 6784, pp. 354-360, 2000.

[85] Shi Du Yan, A. M. Schmidt, G. M. Anderson et al., "EnhanCED cellular oxidant stress by the interaction of advanced glycation end products with their receptors/binding proteins," The Journal of Biological Chemistry, vol. 269, no. 13, pp. 9889-9897, 1994.

[86] H. Ariyoshi, N. Yoshikawa, Y. Aono et al., "Role of receptor for advanced glycation end-product (RAGE) and the JAK/ STAT-signaling pathway in AGE-induced collagen production in NRK-49F cells," Journal of Cellular Biochemistry, vol. 81, no. 1, pp. 102-113, 2001.

[87] M. Andrassy, J. Igwe, F. Autschbach et al., "Posttranslationally modified proteins as mediators of sustained intestinal inflammation," The American Journal of Pathology, vol. 169, no. 4, pp. 1223-1237, 2006.

[88] J. B. Mackic, M. Stins, J. G. McComb et al., "Human blood-brain barrier receptors for Alzheimer's amyloid- $\beta$ 1-40. asymmetrical binding, endocytosis, and transcytosis at the apical side of brain microvascular endothelial cell monolayer," Journal of Clinical Investigation, vol. 102, no. 4, pp. 734-743, 1998.

[89] R. Giri, Y. Shen, M. Stins et al., “ $\beta$-amyloid-induced migration of monocytes across human brain endothelial cells involves RAGE and PECAM-1," American Journal of Physiology, vol. 279, no. 6, pp. C1772-C1781, 2000.

[90] O. Arancio, H. P. Zhang, X. Chen et al., "RAGE potentiates $\mathrm{a} \beta$-induced perturbation of neuronal function in transgenic mice," The EMBO Journal, vol. 23, no. 20, pp. 4096-4105, 2004.

[91] O. Arancio, H. P. Zhang, X. Chen et al., "RAGE potentiates $\mathrm{a} \beta$-induced perturbation of neuronal function in transgenic mice," The EMBO Journal, vol. 23, no. 20, pp. 4096-4105, 2004.

[92] N. Origlia, C. Bonadonna, A. Rosellini et al., "Microglial receptor for advanced glycation end product-dependent signal pathway drives $\beta$-amyloid-induced synaptic depression and long-term depression impairment in entorhinal cortex," Journal of Neuroscience, vol. 30, no. 34, pp. 11414-11425, 2010.
[93] E. Himeno, Y. Ohyagi, L. Ma et al., "Apomorphine treatment in Alzheimer mice promoting amyloid- $\beta$ degradation," Annals of Neurology, vol. 69, no. 2, pp. 248-256, 2011.

[94] I. Vodopivec, A. Galichet, M. Knobloch, A. Bierhaus, C. W. Heizmann, and R. M. Nitsch, "RAGE does not affect amyloid pathology in transgenic ArcA $\beta$ mice," Neurodegenerative Diseases, vol. 6, no. 5-6, pp. 270-280, 2009.

[95] B. O. Fabriek, C. D. Dijkstra, and T. K. van den Berg, "The macrophage scavenger receptor CD163," Immunobiology, vol. 210, no. 2-4, pp. 153-160, 2005.

[96] M. M. J. Polfliet, B. O. Fabriek, W. P. Daniëls, C. D. Dijkstra, and T. K. van den Berg, "The rat macrophage scavenger receptor CD163: expression, regulation and role in inflammatory mediator production," Immunobiology, vol. 211, no. 6-8, pp. 419-425, 2006.

[97] B. O. Fabriek, R. V. Bruggen, D. M. Deng et al., "The macrophage scavenger receptor CD163 functions as an innate immune sensor for bacteria," Blood, vol. 113, no. 4, pp. 887-892, 2009.

[98] E. S. Roberts, E. Masliah, and H. S. Fox, "CD163 identifies a unique population of ramified microglia in HIV encephalitis (HIVE)," Journal of Neuropathology and Experimental Neurology, vol. 63, no. 12, pp. 1255-1264, 2004.

[99] B. O. Fabriek, E. S. Van Haastert, I. Galea et al., "CD163positive perivascular macrophages in the human cns express molecules for antigen recognition and presentation," Glia, vol. 51, no. 4, pp. 297-305, 2005.

[100] M. Minami, N. Kume, T. Shimaoka et al., "Expression of SR-PSOX, a novel cell-surface scavenger receptor for phosphatidylserine and oxidized LDL in human atherosclerotic lesions," Arteriosclerosis, Thrombosis, and Vascular Biology, vol. 21, no. 11, pp. 1796-1800, 2001.

[101] T. Shimaoka, N. Kume, M. Minami et al., "Molecular cloning of a novel scavenger receptor for oxidized low density lipoprotein, SR-PSOX, on macrophages," The Journal of Biological Chemistry, vol. 275, no. 52, pp. 40663-40666, 2000.

[102] D. M. Wuttge, X. Zhou, Y. Sheikine et al., "CXCL16/SR-PSOX Is an Interferon- $\gamma$-Regulated Chemokine and Scavenger Receptor Expressed in Atherosclerotic Lesions," Arteriosclerosis, Thrombosis, and Vascular Biology, vol. 24, no. 4, pp. 750755, 2004.

[103] M. Matloubian, A. David, S. Engel, J. E. Ryan, and J. G. Cyster, "A transmembrane CXC chemokine is a ligand for HIV-coreceptor bonzo," Nature Immunology, vol. 1, no. 4, pp. 298-304, 2000.

[104] S. Mukhopadhyay, J. Herre, G. D. Brown, and S. Gordon, "The potential for toll-like receptors to collaborate with other innate immune receptors," Immunology, vol. 112, no. 4, pp. 521-530, 2004.

[105] D. M. Underhill, "Toll-like receptors: networking for success," European Journal of Immunology, vol. 33, no. 7, pp. 1767-1775, 2003.

[106] B. N. Gantner, R. M. Simmons, S. J. Canavera, S. Akira, and D. M. Underhill, "Collaborative induction of inflammatory responses by dectin-1 and toll-like receptor 2," Journal of Experimental Medicine, vol. 197, no. 9, pp. 1107-1117, 2003.

[107] G. D. Brown, J. Herre, D. L. Williams, J. A. Willment, A. S. J. Marshall, and S. Gordon, "Dectin-1 mediates the biological effects of $\beta$-glucans," Journal of Experimental Medicine, vol. 197, no. 9, pp. 1119-1124, 2003.

[108] K. Hoebe, P. Georgel, S. Rutschmann et al., "CD36 is a sensor of diacylglycerides," Nature, vol. 433, no. 7025, pp. 523-527, 2005. 
[109] H. Maxeiner, J. Husemann, C. A. Thomas, J. D. Loike, J. El Khoury, and S. C. Silverstein, "Complementary roles for scavenger receptor a and CD36 of human monocyte-derived macrophages in adhesion to surfaces coated with oxidized low-density lipoproteins and in secretion of $\mathrm{H}_{2} \mathrm{O}_{2}$," Journal of Experimental Medicine, vol. 188, no. 12, pp. 2257-2265, 1998. 


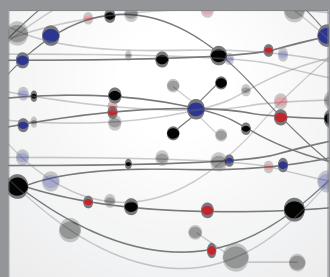

The Scientific World Journal
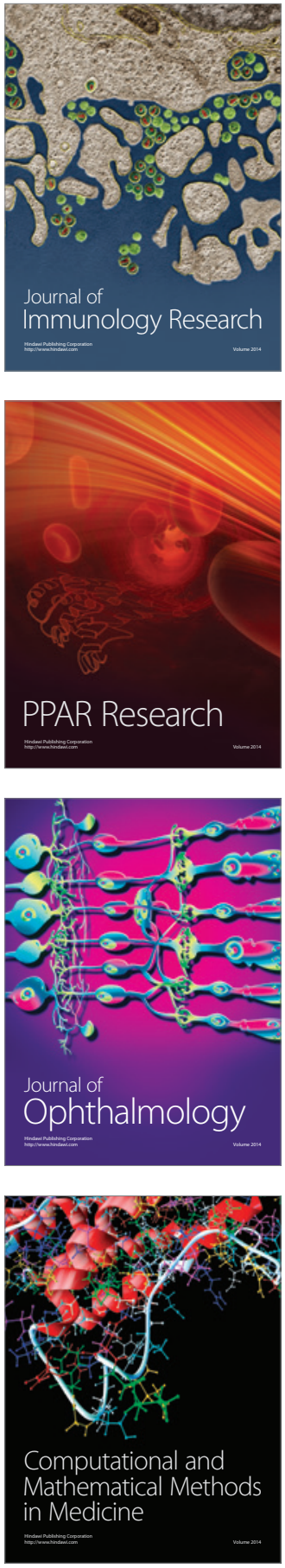

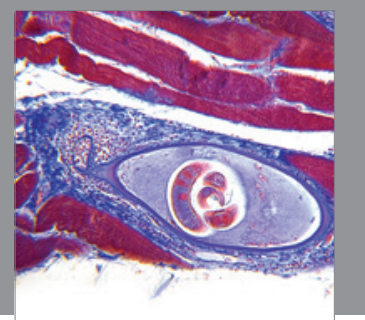

Gastroenterology

Research and Practice
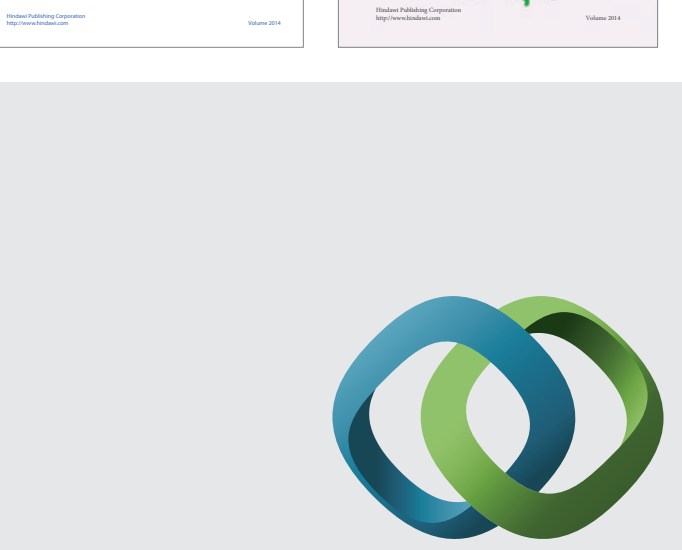

\section{Hindawi}

Submit your manuscripts at

http://www.hindawi.com
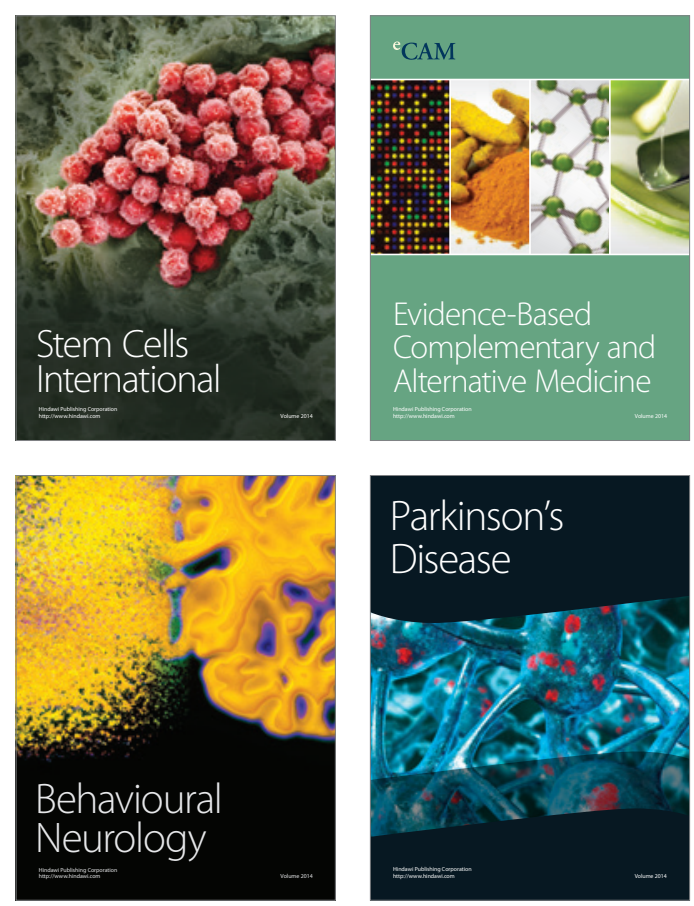

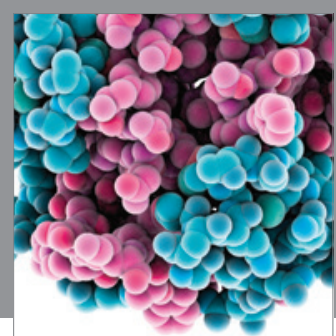

Journal of
Diabetes Research

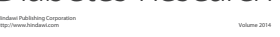

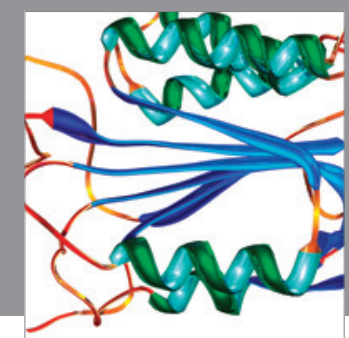

Disease Markers
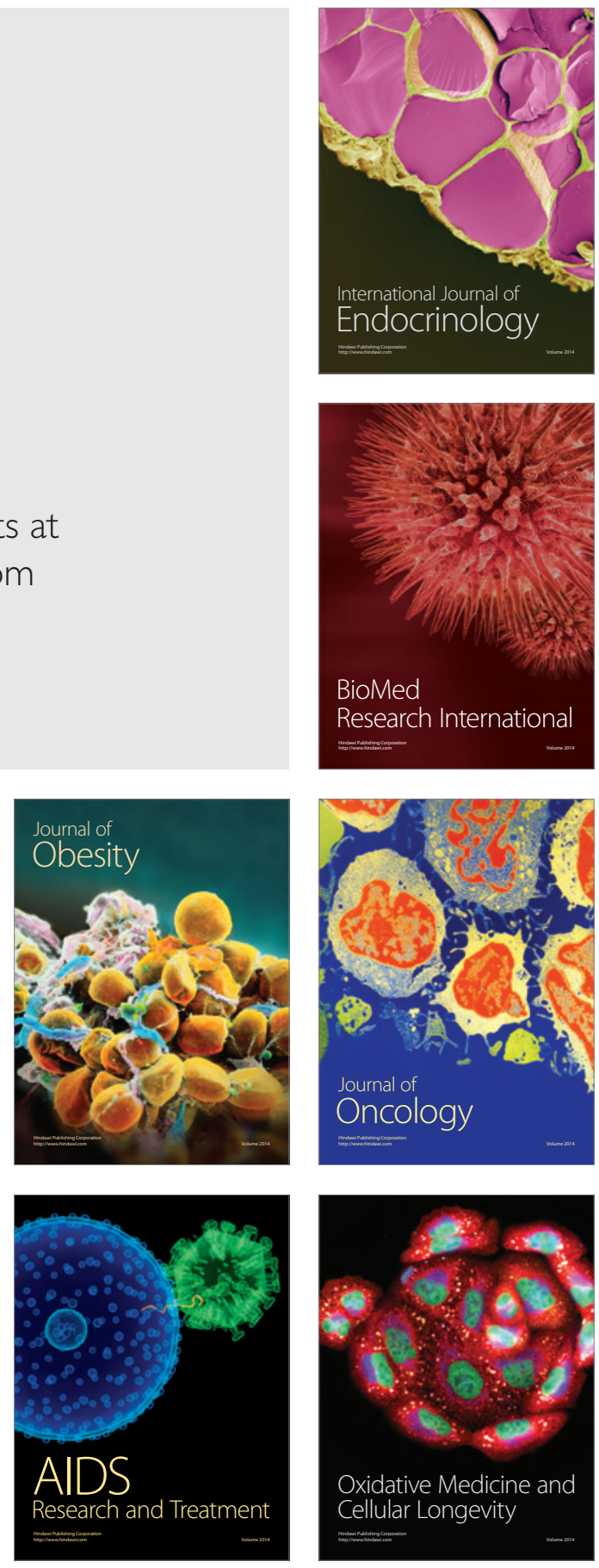